\title{
A FORMAÇÃO DA IDENTIDADE NA EDUCAÇÃO ESCOLAR QUILOMBOLA
}

\author{
THE FORMATION OF IDENTITY IN QUILOMBOLA SCHOOL \\ EDUCATION
}

Alexandre Leidens ${ }^{1}$

\section{RESUMO}

Este artigo objetiva analisar a formação da identidade de crianças e jovens provindos de uma comunidade quilombola e estudantes de uma Escola Quilombola na cidade de Palmas/PR. O trabalho, além de se deter em particularidades do local, se atentará para aspectos históricos e sociais envolvidos na constituição de sua identidade, tendo em vista, além disso, um imaginário social que interfere de inúmeras maneiras nesse processo. Como quesito substancial e fundamental, o artigo se baseará também em uma entrevista realizada com professores e líderes comunitários sobre a educação na localidade. A base teórica do trabalho, na busca por uma observação mais atenta e focalizada do contexto como um todo, será focalizada em autores como Bhabha (2013), Moura (2006) e Rey (2003).

\section{PALAVRAS-CHAVE}

Identidade. Educação. Quilombo. Escola.

\section{ABSTRACT}

This article aims to analyze the constitution of children and young people identity from a quilombola community and students from a Quilombola School in Palmas/PR. The work will focus on historical and social aspects involved in the constitution of its identity, taking into account, in addition, a social imaginary that interferes in innumerable ways in this process. The article will also be based on an interview with teachers and community leaders on education in the locality. The theoretical basis of the work will be focused on authors such as Bhabha (2013), Moura (2006) and Rey (2003).

\section{KEYWORDS}

Identity. Education. Quilombo. School.

1 Mestrando em Letras, pela Universidade Tecnológica Federal do Paraná, Câmpus de Pato Branco. 
A Educação Escolar Quilombola envolve muitos fatores que vão além do conteúdo escolar. A história de resistência e luta, os costumes e as crenças do povo estão latentes em quaisquer manifestações culturais que lhes sejam atribuídas. Soma-se a isso um imaginário social que utiliza de generalizações das mais variadas ordens e os insere em ideias préconcebidas que restringem a história dos inúmeros quilombos existentes no país a um grande relato, único e invariável. Em meio a uma herança de muita luta, tanto contra o sistema que os escravizava, quanto contra o preconceito infundado que sempre os cercou, sobretudo pela cor de sua pele, as comunidades quilombolas, ao longo dos anos, se viram forçadas a lutar da mesma forma, inclusive após a abolição de 1888, contra um sistema que continuou os excluindo e ainda os infla de preconceitos.

A formação da identidade de um quilombola é bastante afetada por essa situação, a busca por uma identidade, por uma cultura, por um grupo no qual se sinta inserido se constituiu como um problema durante muitos anos para todos esses sujeitos, como também para qualquer negro brasileiro. Isso começou a mudar quando esse grande relato começou a ser questionado e se intentou a dar vez e voz aos por muito tempo esquecidos. A história e a cultura quilombola, ainda que de maneira lenta, ganha aos poucos mais espaço nas mais variadas discussões. Essa perspectiva começou a aparecer em um contexto pós-moderno, onde se destaca um questionamento desses grandes relatos e um apelo mais aprofundado às diferentes versões da história, de maneira que sejam abertas possibilidades de ser ela reescrita e revisitada, observando suas inúmeras faces.

Frente a questões como essas e frente a muitos questionamentos que surgem sempre que citadas as comunidades quilombolas e principalmente à Educação Escolar Quilombola, foi realizada uma entrevista em uma Escola Quilombola na cidade de Palmas - PR, onde se reuniram professores e líderes comunitários para responder questões, relatar histórias e vivências da comunidade, de modo que fosse possível observar, ainda que sob algumas nuances, como é o cotidiano de uma comunidade quilombola e em que bases se molda a educação na escola, sobretudo quando ligado à formação do indivíduo, à formação e ao desenvolvimento da identidade e da personalidade do sujeito. Para isso, focalizou-se a formação da identidade 
de crianças e jovens quilombolas, tendo em vista os aspectos históricos e sociais envolvidos nesse quesito, de tal modo que essa análise, ressaltando um imaginário social bastante arraigado e influente se confirmam como o objetivo principal deste artigo. Serão utilizadas, na busca de respostas para esses questionamentos, uma observação mais atenta e focalizada em alguns excertos da entrevista e, como base teórica para a reflexão, serão usadas obras de autores como Bhabha (2013), Moura (2006) e Rey (2003). Embora exista a publicação das Diretrizes Curriculares Nacionais para a Educação Escolar Quilombola na educação básica desde 2012, e, tal como ela, uma série de outras leis e decretos que versam sobre a questão da existência e manutenção das escolas quilombolas, não serão abordados diretamente temas gerais como os direitos adquiridos. Entende-se claramente a importância dessas conquistas para toda a população quilombola, sobretudo para os estudantes que provém desse meio; no entanto, pretende-se focalizar apenas as questões ligadas ao trabalho da escola frente à formação da identidade dos estudantes.

\section{Cotidiano quilombola}

Com histórias, por vezes, diversas, as comunidades quilombolas sofrem com generalizações de toda natureza, sem que haja um conhecimento mais profundo sobre suas origens e práticas culturais. Certamente, o meio de convívio e a interação entre aqueles sujeitos, ou entre seus descendentes, que ficaram por muitos anos convivendo isoladamente, carentes de contato direto com o restante da sociedade, terá sua cultura questionada pelos demais. Cabe o pensamento sobre o desempenho da cultura na vida social e sobre sua influência na formação da identidade do povo quilombola, sobretudo quando há um entrave causado pela psicologia social, que costumeiramente os apregoa preconceitos das mais diversas formas.

Pensando a cultura em uma perspectiva semiótica, será possível entender que ela é formada a partir de uma teia de significados, que, por sua vez, são criados pelo homem. Dessa forma, é perceptível uma tênue linha que leva os sujeitos a observarem de modo característico e pré-concebido toda e qualquer diferença, formando, assim, um imaginário comum sobre 
praticamente toda a sociedade. Nesse contexto, se torna comum que os quilombolas sejam observados a partir das suas particularidades históricoculturais, trazendo sempre a carga sórdida da escravidão aos olhares dos demais. Além disso, os quilombolas carregam em seus ombros a história da resistência e da luta. O imaginário social, entretanto, contorna toda a história da comunidade a partir de um conhecimento comum, onde a tônica é dada pelas ideias pré-concebidas.

A formação da identidade dos sujeitos de uma comunidade quilombola está permeada por esses e muitos outros entraves. Segundo Rey (2003), a identidade pode ser entendida como um produto da ação do indivíduo e da sociedade, de maneira que seja formada uma confluência de forças sociais que operam sobre o mesmo, onde ele possa atuar e construir a si. A identidade se forma envolta à sociedade, o sujeito está ligado de forma intransponível à sociedade da qual é originário e terá sua identidade formada a partir da carga de influências, construída de inúmeras maneiras por ela. Ainda que haja a possibilidade iminente de um distanciamento do sujeito da sociedade que primeiramente o formou, não poderá se desvencilhar por completo. A formação da identidade é um diálogo complexo e volátil entre o sujeito e a sociedade e acontece de forma ininterrupta e abrangente. O sujeito se constitui a partir de um conjunto de informações e zonas de sentido que operam de modo simultâneo. Nesse meio, o imaginário social é o que configura os sentidos, é onde são formadas muitas das experiências do sujeito, de maneira a dar veracidade à produção de sentido, considerando sempre a história do sujeito e de seu sistema de relações. Há, assim, uma dialética do sujeito, onde é visto um caráter complexo, em que todos estão em uma relação recursiva e plurideterminada, simultaneamente manifestada pela ação do outro (REY, 2003).

A identidade quilombola acontece em meio a representações e interpelações dentro dos costumes da comunidade, a partir das identificações com alguns valores e significados que são construídos socialmente. É importante notar, também, que a coletividade é essencial nesse meio, sobretudo quando se trata do contexto histórico-cultural, onde ocorre um reconhecimento dos sujeitos enquanto grupo. A troca 
de histórias e relatos, os valores e costumes estão ligados a um passado em comum, de tal maneira que seja criada uma ideia de identidade compartilhada. Isso se dá pelo sentido e pela significação dos discursos, narrativas, contos e fatos sobre a história do grupo, sendo essa, ainda, construída por representações e relatos, na maioria das vezes orais, sobre as manifestações culturais e sociais do grupo. A cultura, por sua vez, é compreendida como uma grande construção de significados, que são criados pela sociedade e que dão a possibilidade de uma análise a partir de uma perspectiva social aos envolvidos.

Grande parte, se não todo o imaginário coletivo quanto aos quilombolas se dá com base na época escravocrata, onde, de fato, começaram a surgir os primeiros quilombos no país. A enorme proporção em que ocorreu o tráfico de escravos em praticamente todo o território nacional frisa ainda mais a influência dessa época para as futuras gerações na constituição e a formação histórico-cultural da identidade não só quilombola, como também brasileira. Isso extrapola questões ligadas à etnia, ao local de onde foram forçosamente trazidos, à cultura e à língua da qual foram separados para começar a formar ou modificar, desde então, a história e a cultura brasileira.

Há registros de que a palavra quilombo foi trazida para o Brasil e a toda a América por negros africanos escravizados, assumindo sentidos diversos em épocas e regiões diferentes. Esse vocábulo, juntamente com seu conteúdo militar e sociopolítico, remete-se a povos africanos de línguas bantu, como os Imbangala, os Mbundu, os Kongo, os Ovimbundue e os Lunda, apesar de ser originariamente da língua umbundu (CALHEIROS; STADTLER, 2010, p. 135).

A palavra quilombola em si traz um estereótipo que remete a uma comunidade antiga, formada por escravos fugitivos, que se agrupavam para conseguir sobreviver. Há, também, a suposição de que teriam desaparecido depois da abolição, em 1888. É comum também ser encontrada uma visão romantizada, que observa os quilombolas como uma comunidade onde permanecem as raízes culturais africanas ainda intocadas, onde não houve nenhuma miscigenação: "como resposta ao tratamento hostil e violento empregado aos escravos, os quilombos, ressaltam a escravidão na constituição e formação da identidade dos quilombolas, da representação 
de suas culturas e da introjeção de aspectos pertinentes à subjetividade desses indivíduos" (FURTADO; PEDROSA; ALVES, 2014, p. 112). Além disso, é claramente perceptível que houve e ainda há uma resistência bastante grande quanto ao povo quilombola e quanto à cultura africana em si, ainda que tenham sido muito importantes na formação social e cultural do Brasil nos últimos séculos.

No entanto, ainda hoje algumas práticas de resistência podem ser observadas, pois as comunidades quilombolas são um exemplo de não inserção na identidade hegemônica. Há uma construção contínua da identidade quilombola, que se configura como uma identidade de luta e resistência, em um primeiro momento, contra a sua própria escravização e, hoje em dia, contra a invisibilidade que lhes é dada, seja em um âmbito cultural, seja em um âmbito social. Nesse meio, observa-se, como visto antes, que há, na formação da identidade quilombola, não apenas o sujeito em si, mas também uma grande influência do meio social do qual provém. De tal maneira que se denominar ou se reconhecer como quilombola é resultado de uma identidade construída socialmente, onde há uma demarcação de poder em que há a resistência a uma posição que se revela estigmatizada desde a época da escravidão até os dias de hoje (CALHEIROS; STADTLER, 2010).

\section{A identidade em uma escola quilombola}

A formação da identidade quilombola é bastante complexa e envolve múltiplos fatores. Alguns meios para fortalecimento da sua cultura são vistos atualmente, sobretudo para fugir aos estereótipos pré-concebidos e para que possa formar sua identidade de maneira saudável, tendo em vista a história da sua comunidade e do meio familiar onde está o sujeito inserido. Um desses meios é o utilizado pelas escolas quilombolas, onde a história, a cultura e os valores da comunidade são temas constantes e analisados de maneiras claras e objetivas. Para uma análise da formação da identidade não apenas dos estudantes, mas também da comunidade quilombola em si, foi realizada uma entrevista com os professores e líderes comunitários na Escola Quilombola Maria Joana Ferreira, no município de Palmas PR. A entrevista aconteceu em meados do segundo semestre do ano de 
2017 e objetivou uma observação mais próxima da realidade enfrentada pela comunidade, tanto nos quesitos escolares, como nos quesitos sociais. Dessa entrevista, foram extraídos alguns excertos para posterior análise e discussão, com foco na formação da identidade quilombola no local.

Como frisado anteriormente, há um estereótipo bastante forte construído durante séculos voltados aos quilombolas e aos negros, estes últimos, ainda que não pertencessem às comunidades quilombolas ou que sequer tenham sido escravizados, tendo imigrado para o Brasil em um período posterior à escravidão, sofrem preconceito pela cor de sua pele. Isso demonstra uma incongruência significativa, pois dados oficiais reportam aos negros e pardos a maioria da população brasileira. Se considerada a pesquisa realizada pelo IBGE em 2015, será perceptível que negros e pardos juntos somam um contingente de 53,92\%, ao passo que a população que se autodeclara branca soma um total de $45,22 \%$. Ainda que estejam em números não muito distantes, brancos, negros e pardos somam a maioria absoluta da população brasileira, deixando para as demais etnias uma pequena fatia da população. Não se está aqui afirmando, de maneira alguma, que as minorias devem ou deveriam sofrer com preconceitos das mais variadas formas, se está apenas observando e apontando a total falta de congruência, no que tange ao imaginário coletivo no Brasil, que destina à maioria um preconceito e uma ideia de submissão ou subserviência construído há séculos, em uma época escravagista, onde a maior reação possível era, de fato, unirem-se e estruturarem-se em quilombos. Sobre esse aspecto histórico, é importante observar que em fala de professores da Escola Quilombola é possível perceber que estão cientes de toda a realidade que cerca os seus estudantes e trabalham para que eles consigam reagir de modo coerente aos estereótipos e preconceitos provindos de um imaginário social que, embora incoerente, é dominante e degradante.

o resultado também está nos nossos alunos porque além do conhecimento eles levam a maneira que... pra lá fora há casos de racismo... há casos de desvalorização eles sabem reagir né?... porque muito tempo foi deixado de lado... os alunos que eram negros não tinham a sua história contada na escola... então acontecia um caso... olha acho que não é... não foi isso, agora eles sabem levar bem o correto... eles sabem ter argumento né? pra falar o que é o certo e o que errado... você sabe que você ta plantando uma sementinha porque eles 
não vão ficar só aqui no bairro né? eles estão indo estudar no instituto eles estão indo trabalhar... eles vão saber contar o real né? o certo porque muitas vezes foi equivocado né? A história.”

Nesse comentário, proferido por uma das professoras da escola, percebe-se uma preocupação bastante grande com o imaginário social e com os problemas dele advindos. Há, também, a clara demonstração de que a escola e a comunidade quilombola são refúgios, onde eles podem encontrar apoio contra todo um conjunto de preconceitos que sofrem quando estão fora desse meio. $\mathrm{Na}$ escola e na comunidade eles estão incluídos em um sistema do qual fazem parte e onde encontram manifestações bastante consistentes de sua cultura, onde encontram sua história e seu meio de viver entre seus semelhantes, onde conseguem se sentir parte de um meio que enfrenta, grosso modo, os mesmos problemas e as mesmas preocupações, ainda, de certa forma, mantendo as raízes fundamentais de um quilombo, onde os escravos podiam encontrar apoio incondicional e esquecerem os problemas encontrados fora desse local. A entrevistada cita casos de racismo e desvalorização como exemplos de situações que frequentemente os estudantes enfrentam e que, sobretudo antigamente, eram aceitas como verdades, sem que fosse dada voz aos estudantes e moradores da comunidade. Há, então, a procura da escola por uma maneira com que os alunos consigam se autoafirmar e de não deixar que se criem estigmas ou algum complexo de inferioridade entre os estudantes, principalmente por haver essa preocupação com a formação da sua argumentação no sentido de defender sua cultura e saber lidar com casos de desvalorização e preconceitos, seja para contra argumentar algum comentário, seja para saber denunciar casos mais graves de racismo. Essa ação é essencial, pois, como relatado, os estudantes não permanecem apenas na comunidade, mas saem para estudar, trabalhar e viver em outros lugares. Quanto mais souberem sobre a sua cultura, quanto mais informações, argumentos e conhecimento sobre a sua história eles tiverem, menor vai ser a chance de sofrerem com estigmas provindos do imaginário social.

Muito embora a questão da negação do outro seja latente, destacase a consciência de uma identidade étnica e a relação de pertencimento a 
uma comunidade que vai se construindo aos poucos, na valorização das suas características, da sua história, da sua cultura e das suas crenças. A identidade se forma, assim, na afirmação do que é seu, no sentimento de pertencimento e na afirmação do cunho cultural e até ideológico em prol da sua identificação étnica, cultural e histórica. É justamente negando a cultura do outro como ideal sobreposto por um imaginário social pré-determinado e fortalecendo a sua própria identidade que acontece a virada na perspectiva de leitura da realidade tida pelos sujeitos e estudantes quilombolas. O papel social da escola quilombola e da comunidade como um todo, nesse sentido, é fundamental e tão importante quanto o conhecimento enciclopédico, matéria por matéria, trabalhado costumeiramente nas escolas. Saber as outras versões da história e poder disseminar os pontos de vista das comunidades quilombolas, que sofreram durante séculos e ainda sofrem com um preconceito infundado é questão sine qua non para o desenvolvimento humano, intelectual e social desses estudantes.

Nesse sentido, observar o que diz Bhabha (2013) pode ser bastante significativo. $\mathrm{O}$ autor conceitua o hibridismo e a tradução cultural para compreender alguns efeitos da espacialização do tempo na mudança das visões culturais, histórias e ainda ideológicas da modernidade para a pósmodernidade e para a pós-colonialidade. Anteriormente, existia uma visão de que o tempo histórico era linear e totalizante, hoje em dia percebe-se que isso servia como uma estratégia para impor um conceito de tempo e história sobre os conceitos correspondentes e co-existentes de outros, que antes ficavam no escuro. Dessa forma, pode-se dizer que nunca houve um conceito único ou ainda puro de tempo; pelo contrário, sempre existiram inúmeros conceitos, de forma híbrida. Esse processo é visto não apenas na tentativa de ocultar outras partes da história, mas também em aspectos culturais, ideológicos e tecnológicos, que só agora, nos últimos anos, estão ganhando espaço para discussões e debates. Assim, ainda que de modo pequeno, dá-se voz a quem nunca a teve e começa-se a ouvir, ver e compreender as suas visões de mundo, as suas versões da história, as suas maneiras de entender a realidade. Percebe-se, assim, que as grandes narrativas deixam de lado as perspectivas particulares e escondem seus 
locais de origem, de tal maneira que parecem não ter sido construídas por ninguém, deixando, de uma forma ou outra, a impressão de estar falando apenas a verdade, sem que haja possibilidade alguma de questionamento.

As ocorrências em que são vistas atitudes racistas ou preconceituosas contra a comunidade quilombola provém de um imaginário coletivo criado sob os vértices de uma grande narrativa, onde a voz da comunidade nunca fora ouvida ou fora deixada sumariamente de lado. Nesse ínterim, a escola se torna importante pelo motivo de incluir não apenas quilombolas ou descendentes destes, mas também todos aqueles que se sentirem excluídos de alguma forma em outros meios escolares. A escola quilombola, na comunidade em geral, é vista como um meio para que estudantes que se sintam excluídos em quaisquer outros lugares possam se desenvolver de modo sadio e consistente, como pontuou outro professor:

É uma diversidade, uma inclusão... como é a inclusão de alunos de todos aí... é professores também... O que nós dizemos... nós não queremos que aconteça, agora o que acontecia no passado, que nós éramos excluídos da sala de aula, meu padrasto contava que tinham que pagar um professor na comunidade, pra dar aulas nas casas, né... dos negros, porque não podiam estudar juntos... depois com o tempo que foi mudando aos pouquinhos as mentalidades né... então... e hoje aqui nós temos uma inclusão de alunos.

Percebe-se que a diversidade é um fator sempre lembrando e enfatizado pelos professores entrevistados. A escola funciona como um agente de inclusão de alunos oriundos de várias partes da cidade que tiveram algum tipo de problema em outras escolas. Os quilombolas, nesse caso, acolhem muito mais do que são acolhidos quando saem da comunidade. Outro fator que deve ser destacado desse relato é a questão histórica que envolvia os estudos na comunidade quilombola, onde o imaginário social e o preconceito eram ainda mais latentes e sequer eram escondidos pelo fato de não serem aceitos quilombolas nas outras escolas. Isso dá evidência a um sério problema social, um descaso evidente e uma falta de comprometimento com a educação não só de autoridades, como também de profissionais da educação que não aceitavam esses estudantes em suas salas de aula. O constructo social, recheado de ideias pré-concebidas sobre os negros, sobre a comunidade quilombola, sobre toda a história de uma comunidade chega a um alto nível, que lembra um 
provincianismo infantil, pois, de uma forma ou outra, se esteve, por muito tempo, tirando a possibilidade de uma criança quilombola aprender, de frequentar as aulas apenas pelo fato de ser dessa comunidade e ter a cor da pele diferente. Nesse sentido,

O silenciamento ou a falta de ação da escola no combate ao preconceito e à discriminação racial produz efeitos na identidade dos sujeitos, nas formas de se ver e de conceber o grupo a que pertence. A escola é uma instituição que contribui para a formação dos sujeitos, um espaço sócio-cultural de trocas, diálogos, confrontos e acordos, e, por isso, é necessário atentar-se para aquilo que transmite intencionalmente ou não, no que se refere aos conteúdos e às práticas (SOUZA, 2009, p. 158).

A escola tem um papel fundamental na constituição do sujeito, pois a ela cabe também a discussão de questões não apenas objetivas, mas também subjetivas, que deslocam e motivam o alargamento de fronteiras no pensamento dos estudantes, aumentando os seus horizontes históricos, questionando, sempre que possível, as suas verdades pré-concebidas e repensando as grandes narrativas, tão comuns e disseminadas na sociedade atualmente.

Ainda tratando da questão da cor da pele, percebe-se que a construção da identidade do quilombola é bastante envolta a esse quesito, principalmente por existirem muitos equívocos sobre essa que é uma das questões mais controversas e que causam mais preconceitos e leituras incorretas da comunidade. Um exemplo é o relato de uma das professoras entrevistadas que, quando fala sobre a visão das pessoas de fora da comunidade para com eles, retrata uma grande falta de conhecimento até com certa dose de humor:

Nós temos como diz, nem todo quilombola é negro, e nem todo negro é quilombola... daí tem pessoas que dizem que é negro e dizem... ah, eu sou carambola (risos)... ontem até um homem veio dizendo... ah eu queria fazer o PSS [trata-se do Processo Seletivo Simplificado do Paraná, por meio do qual há a contratação de professores não concursados para trabalharem em escolas públicas] no edital carambola... (risos) carambola é uma fruta gente... (risos).

Embora bem humorado, o breve comentário da entrevistada suscita muitos questionamentos. Em primeiro lugar, há a questão da cor da pele, que aparentemente é de desconhecimento inclusive dos próprios negros, 
que, por sua vez, também fazem uma leitura da realidade quilombola que se assemelha a do imaginário coletivo. Quando a entrevistada ressalta que nem todo negro é quilombola e nem todo quilombola é negro, traz à reflexão uma perspectiva histórica bastante importante e obscura ainda aos debates, ainda mais ao senso comum, que trata justamente da formação dos quilombos, da origem dos quilombolas e da constituição de uma sociedade dentro dos seus moldes. Pode-se observar que não apenas de negros escravizados eram formados os quilombos, Moura afirma que "merece destaque a epopeia dos Palmares, em Alagoas, que resistiu por mais de cem anos aos ataques dos escravocratas. Lá viviam em comunhão ex-escravos, indígenas e não negros perseguidos pela colônia” (MOURA, 2006, p. 331). Assim como no Quilombo dos Palmares, os demais quilombos podem ser considerados um refúgio para demais pessoas que, por um motivo ou outro, optam pela resistência e se juntam à comunidade. Seguindo o comentário da entrevistada, observa-se em tom anedótico uma situação vivida por ela que transpassa um desapontamento frente ao desconhecimento do indivíduo. Toda a luta enfrentada pela escola e pela comunidade para o reconhecimento da cultura quilombola, dos costumes, da história da comunidade são postos em xeque quando alguns comentários dessa natureza aparecem. De fato, isso evidencia que há ainda muito o que fazer para esse reconhecimento, não apenas em um plano social, mas também em um meio educacional, uma vez que a pessoa em questão, aparentemente se trata de um professor interessado em trabalhar como contratado na escola quilombola.

Mesmo com equívocos dessa natureza e problemas advindos dessas leituras superficiais sobre a Escola Quilombola, há, em um contexto macro, em uma ótica mais abrangente, a clara desestabilização dos estigmas sociais quando implantada a Educação Escolar Quilombola, pois, de uma forma ou outra, a educação em um meio especificamente quilombola acaba com o imaginário coletivo de que há uma inserção subalterna da população negra na sociedade e, além disso, no seu sistema escolar. Embora regulamentada, as comunidades em si enfrentam adversidades no que tange à educação, uma vez que não há escolas em todas as comunidades quilombolas e, 


\section{ARTIGO}

muitas vezes, quando existem, se encontram instaladas em condições bastante precárias (MIRANDA, 2012).

É possível extrair da entrevista um exemplo das adversidades encontradas pelo estudante quilombola quando inserido em uma escola não quilombola, que demonstra muitos dos preconceitos arraigados na sociedade e ao imaginário social, relatado por uma das entrevistadas, em fala sobre o ocorrido com seu filho:

(...) ele chegou muito feliz ele falou - mãe você vai ficar orgulhosa da minha fada - e eu falei - é? deixa eu ver - dá ele fazia, quando ele me mostrou a fada dele era marrom e preta... e era LINDA né? e ele usou um pouco de rosa e um pouco de roxo... e daí eu falei - e a sua professora falou o que? ela falou (...) ela falou que era diferente mas que era linda.

Essa situação relatada na entrevista é bastante complicada e faz com que se reflita sobre o que, de fato, é a cor da pele e o que isso significa para a sociedade em si. Fica aparente também não apenas a questão do preconceito, mas também o despreparo da professora frente ao acontecido. Para ela, não há ou não havia nenhuma possibilidade de uma fada não ser branca, de maneira que sofreu um baque quando se deparou com a pintura do aluno e deixou transparecer isso na sua fala. A formação da identidade de uma criança quilombola perpassa por todos esses entraves e problemas, ressalvas e surpresas que, muitas vezes, podem ocorrer sem que os demais percebam que estão influenciando negativamente na sua percepção de mundo e na formação de sua personalidade. Entretanto, apenas pelo fato de poderem citar uma situação como essa e de perceber que isso é uma incongruência evidente, que influencia diretamente na formação da identidade de um quilombola já se pode observar que o sujeito não está mais em um contexto modernista, onde há uma perspectiva de homogeneidade, uma história única e invariável, mas, pelo contrário, se está em um contexto pós-moderno, onde o sujeito se enxerga em um cruzamento de histórias, culturas e até ideologias múltiplas, heterogêneas, que dão inúmeras variações e faces para a formação de sua identidade. Nesse sentido, há que se destacar o hibridismo não como um efeito subalterno de consequência entre o contato de elementos puros e heterogêneos, mas sim como um processo de formação, muitas vezes conflitantes, que 
ocorrem de forma dinâmica e incessante entre linguagens, identidades, culturas, onde o hibridismo é afetado e afeta, é escrito e reescrito, em uma veia onde não há chegada previsível, tampouco consequências prédeterminadas, sem garantia nenhuma, em um processo tido por Bhabha (2013), como tradução cultural. A tradução cultural em um contexto pós-moderno é substancial para a formação da identidade do sujeito quilombola. Embora ainda exista um imaginário coletivo que, grosso modo, atua de forma contrária ao pensamento coerente e à valorização da cultura quilombola, a percepção de que se está localizado dentro de uma cultura que por muito tempo foi marginalizada e que luta contra ideias pré-concebidas e estereótipos até hoje é fundamental não apenas para a sua identidade, mas também para o reconhecimento da sua cultura, da sua comunidade, da sua história.

Para concluir, é preciso destacar que este artigo objetivou fazer uma análise da formação da identidade de crianças e jovens quilombolas, tendo como base aspectos históricos e sociais que estão, inevitavelmente, envolvidos nesse processo. O imaginário social constituído durante séculos num país que sempre viu o negro e, sobretudo, o quilombola envolto em uma gama de preconceitos irrevogáveis foi relevante para a breve análise feita por este trabalho, bem como a questão da concepção pós-moderna de hibridismo e tradução cultural, principalmente, no que concerne à compreensão de efeitos de espacialização do tempo, modificações nas perspectivas culturais, históricas e ideológicas.

O cotidiano de uma escola e de uma comunidade quilombola aparentam ser diversos de uma escola comum em um bairro qualquer, pois, além de se preocupar com a educação dos seus estudantes, que por si só já se configura como uma grande tarefa, com suas matérias e seu conteúdos programáticos, constantemente se ocupam em abordar diferentes maneiras de desconstrução do imaginário social que afeta diretamente a formação da identidade dos que pertencem a esse meio. Esse aspecto do é importante não apenas para os estudantes, mas para a comunidade como um todo, que dialoga de várias formas com esse conhecimento. Evidentemente, por ser essa uma questão fundamental na escola quilombola, o fomento ao pensamento crítico-reflexivo dos estudantes é aguçado inclusive pela 
reflexão sobre o seu cotidiano, de tal forma que se preparam melhor para enfrentar as adversidades causadas pelo imaginário social frente à sua condição de quilombola e, com base nisso, também desenvolvem um maior aproveitamento na escola, manifestando crescimento intelectual e humano. Percebeu-se que a questão da formação da identidade é vista com cautela e atenção na escola quilombola, de maneira a se prezar por uma construção identitária que valorize a cultura, a história, a religião e as características do povo quilombola e não desmereça em nenhuma ordem o ser humano e o grupo ao qual pertence. Essas ações acontecem de maneira sutil, objetivando a afirmação cultural ou a mudança de perspectivas, quando necessário, dos estudantes, trabalhando para que se sintam inseridos no meio do qual provém e passem a sentir orgulho das particularidades da cultura quilombola. Por fim, intui-se que essa preocupação dos professores com a continuidade da cultura quilombola em diálogo com os estudantes é uma questão essencial na sua formação identitária.

\section{Referências}

BHABHA, H. K. O local da cultura. Tradução de Myriam Ávila, Eliana Lourenço de Lima Reis e Gláucia Renate Gonçalves, 2. ed., Belo Horizonte: Editora UFMG, 2013.

CALHEIROS, F. P; STADTLER, H. H. C. Identidade étnica e poder: os quilombos nas políticas públicas brasileiras. Revista Katálysis, 13, v.1, pp. 133139. Disponível emhttp://www.scielo.br/pdf/rk/v13n1/16.pdf. Acesso em 26/12/17.

FURTADO, M. B; SUCUPIRA, R. L; ALVES, C. B. Cultura, identidade e subjetividade quilombola: uma leitura a partir da psicologia cultural. Psicologia \& Sociedade, 26, v.1, pp. 106-115.

GONZÁLEZ-REY, F. Sujeito e subjetividade: uma aproximação históricocultural. São Paulo: Thomson, 2003.

MIRANDA, S. A. Educação escolar quilombola em Minas Gerais: entre ausências e emergências. Revista Brasileira de Educação. 17, v.50, pp. 369-383. Disponível emhttp://www.scielo.br/pdf/rbedu/v17n50/v17n50a07.pdf. Acesso em 27/12/17.

MOURA, G. Quilombos contemporâneos no Brasil. In: CHAVES, R; SECCO, C.; MACÊDO, T. (Orgs.). Brasil África: como se o mar fosse mentira. São Paulo: Editora UNESP/Luanda, Angola: Chá de Caxinde, 2006, pp. 327-362. 
OLIVEIRA, R. C. de. Identidade, etnia e estrutura social. São Paulo: Livraria Pioneira Editora, 1976.

SOUZA, M. L. A. de. Educação e identidade no Quilombo Brotas. Campinas (SP):Unicamp, 2009 [Dissertação de Mestrado em Educação).

Data de recebimento: 29/04/2018

Data de aceite: 30/05/2018 